\title{
Liocourt - Alaincourt-la-Côte
}

RD 955, déviation de Liocourt

Florent Jordy

\section{(2) OpenEdition}

Journals

Édition électronique

URL : http://journals.openedition.org/adlfi/8778

ISSN : 2114-0502

Éditeur

Ministère de la culture

Référence électronique

Florent Jordy, «Liocourt - Alaincourt-la-Côte », ADLFI. Archéologie de la France - Informations [En ligne], Lorraine, mis en ligne le 01 mars 2001, consulté le 01 mai 2019. URL : http://journals.openedition.org/ adlfi/8778

Ce document a été généré automatiquement le 1 mai 2019.

(c) Ministère de la Culture et de la Communication, CNRS 


\title{
Liocourt - Alaincourt-la-Côte
}

\author{
RD 955, déviation de Liocourt
}

\section{Florent Jordy}

\author{
Identifiant de l'opération archéologique : F1357200100076A \\ Date de l'opération : 2001 (SU)
}

1 Suite à l'intervention de diagnostic menée dans l'emprise de ce projet de déviation, les trois sites mis en évidence ont fait l'objet d'une fouille préventive, en novembre et décembre 2001.

2 À Liocourt « les Grands Champs » un décapage sur environ $500 \mathrm{~m}^{2}$ a montré l'absence de vestiges structurés hormis un fossé (parcellaire?) d'un mètre de large. De probables niveaux colluvionnés, piégés dans deux zones dépressionnaires, ont livré de la céramique protohistorique fragmentée (Hallstatt moyen et final ?).

3 Six cent mètres plus au sud, toujours sur le territoire de Liocourt, au lieu-dit « la Grande Saule ", une surface d'environ $3200 \mathrm{~m}^{2}$ a été ouverte, révélant trois phases principales d'occupation.

4 Un groupe de quatre sépultures à incinération, dont trois déposées en urnes, a été mis au jour en bordure est du décapage. L'une d'entre elles comprenait un petit vase tronconique à décor incisé, attribué au Bronze final IIa. Une autre, contenue dans une jarre à col, était accompagnée d'une petite tasse à anse, d'un petit vase tronconique et d'une écuelle tronconique (Fig. $\mathrm{n}^{\circ} 1$ : Mobilier du site 2, « la Grande Saule », structure 73).

5 Une deuxième phase d'occupation, située au Hallstatt, correspond à un habitat pour lequel deux états ont été distingués. Dans un premier temps, trois tronçons de palissade semblent structurer la zone reconnue, dans laquelle sont implantés deux unités d'habitat de $12 \mathrm{~m} \times 6 \mathrm{~m}$ et de $4 \mathrm{~m} \times 3 \mathrm{~m}$ et deux greniers à 4 poteaux. Au deuxième état sont rattachés deux bâtiments de $6 \mathrm{mx} 4 \mathrm{~m}$ et de $7 \mathrm{mx} 4 \mathrm{~m}$ à $5 \mathrm{~m}$, un grenier à 4 poteaux et une vaste fosse dépotoir. Cette dernière a fourni un corpus de 38 formes céramiques, autorisant une datation probable au Hallstatt moyen (Ha D1) ou éventuellement au début du Hallstatt final (Ha D2). 
6 La période gallo-romaine est, quant à elle, marquée par la présence d'une clôture (avec clayonnage ?) et d'une palissade parallèles, axées nord-est - sud-ouest, et d'une demidouzaine de structures linéaires (drains, fossés et conduite) traduisant une volonté d'assainir le terrain.

7 Le dernier site, reconnu sur près de $3800 \mathrm{~m}^{2}$, est localisé à Alaincourt-la-Côte, au lieu-dit «les Quarottes».

$8 \mathrm{Au}$ nord-ouest de la zone décapée ont été rencontrées quatre vastes dépressions, d'environ $250 \mathrm{~m}^{2}$ chacune. Pour l'une d'entre elles au moins, un empierrement en facilitant l'accès pourrait indiquer une utilisation comme zone d'abreuvoir.

9 Postérieurement au colmatage de ces mares, trois chemins orientés nord-est - sud-ouest et d'une largeur de 2,50 $\mathrm{m}$ à 4,50 $\mathrm{m}$ ont été aménagés, deux d'entre eux étant séparés par un fossé d'un peu plus de $2 \mathrm{~m}$ de large. À une vingtaine de mètres au sud-est de ces derniers, un décapage limité a permis de dégager un bâtiment rectangulaire de $9 \mathrm{~m} \times 7,50 \mathrm{~m}$ en pierres, subdivisé intérieurement en deux pièces, et se rattachant à un angle de mur dont l'extrémité n'a pu être suivie. La démolition a livré de la céramique attribuée à la fin du II $s$. Plus à l'ouest, quelques aménagements en matériaux légers (palissade, bâtiment, etc.), non datés, pourraient appartenir au même ensemble.

\section{ANNEXES}


Fig. $\mathrm{n}^{\circ} 1$ : Mobilier du site 2, " la Grande Saule », structure 73

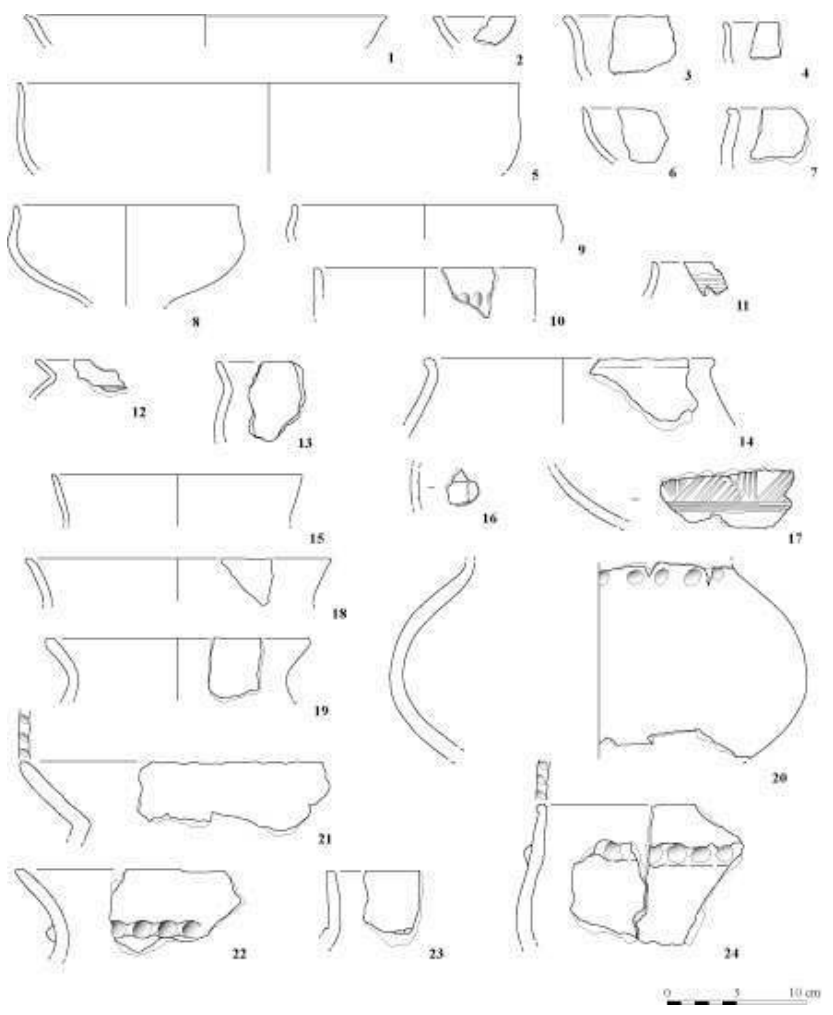

Auteur(s) : Mentélé, S.. Crédits : Mentélé, S. (2001)

INDEX

operation Sauvetage urgent (SU)

Thèmes : abreuvoir, céramique, dépotoir, drain, édifice, fossé, grenier, incinération, palissade, sépulture, tasse, urne, vaisselle

Index géographique : Lorraine, Moselle (57), Liocourt

Index chronologique : âge du Bronze, âge du Fer, Empire romain

\section{AUTEURS}

\section{FLORENT JORDY}

AFAN 